\title{
EFFECTS OF OVERSEAS ADAPTION ON JOB SATISFACTION OF EXPATRIATES IN TEXTILE INDUSTRY
}

\author{
Lin Chien-Hsiung', Shieh Chich-Jen² \\ ${ }^{1}$ National Kaohsiung University of Hospitality and Tourism, Department of Hospitality and M.I.C.E Marketing Management, Taiwan, ROC \\ ${ }^{2}$ Chang Jung Christian University, Department of International Business, Taiwan, ROC \\ E-mail: axel@mail.nkuht.edu.tw, charles@mail.cjcu.edu.tw
}

\begin{abstract}
:
Opening a factory overseas requires a large amount of capitals and technical experiences, and the number of native cadres expatriated overseas is also considerable. The relationships between Overseas Adaption and Job Satisfaction of expatriates are worth research and exploration. This study, therefore, aims to discuss the effects of Overseas Adaption on Job Satisfaction of expatriates in textile industry. The questionnaires for expatriates of Far Eastern New Century are distributed and collected through mails. With convenience sampling, a total of 400 copies are distributed and 263 valid ones are retrieved, with the retrieval rate of $66 \%$. Based on the statistical analyses with SPSS, the sample data are further proceeded with factor analysis, reliability analysis, regression analysis, and analysis of variance. The research findings show the significantly positive correlations between (1) Overseas Adaption and Needs for Survival, (2) Overseas Adaption and Needs for Relatedness, and (3) Overseas Adaption and Needs for Growth; and (4) the correlations between Overseas Adaption and Job Satisfaction show remarkable differences in personal attributes.
\end{abstract}

\section{Keywords:}

Overseas adaption, job satisfaction, textile industry

\section{Research background and motivation}

The rapid economic growth in the past half century had the industrial structure in Taiwan be transited and promoted. The government also formulated acts of industrial encouragement to enhance and assist in businesses that the industry in Taiwan was indeed prosperously developed. Nevertheless, economic globalization resulted in the fierce competition in the international market. After traditional industries in Taiwan experiencing the phases of prenatal developmentdevelopment period-period of maturity, Lin [1] stated that the increasing labour wages and products costs had China and Southeast Asian countries face unprecedented challenges, the advantages were getting into the recession, and hightechnological electric and biomedical industries were taking over [2]. The industrial model in Taiwan used to be production orientation, in which low-cost production with dense labour and low wage was practiced to create the miracle that Taiwan became one of the Four Asian Tigers with Singapore, South Korea, and Hong Kong. Textile industry, outshone in the industries in Taiwan since 1950, enhanced the economic prosperity, provided numerous employment opportunities, and earned enormous foreign exchanges for being famed Taiwan Miracle internationally. However, being an island economy, the economic resources rely on imports and domestic market is small that product export is regarded as the exit of economic development in Taiwan. The emergence of Mainland China and Southeast Asian countries, with extremely low labour costs, has reduced the competitiveness of industries in Taiwan. Under such adverse factors, small-scale or weak- finance textile businesses in Taiwan have been downsized or knocked out. The remaining large-scale and betterfinance businesses are facing the dilemma of no downstream processing, as dyeing and finishing factories have moved out because of the shrinking market in textile industry. In this case, Huang [3] instructed that abundant production equipment in textile businesses has forced to move to China or Southeast Asian countries with low wages, such as Vietnam, Indonesia, Malaysia, Thailand, and Kingdom of Cambodia. In addition to large amount of capitals, such businesses opening factories overseas face the major problems of expatriates' overseas adaption and job satisfaction.

\section{Literature review and hypothesis deduction}

\section{Overseas adaption}

Expatriates' anxiety or moods not adapting to strange or unfamiliar environments and culture are regarded as culture shock [4]. In other words, an individual often face uncertainties and are not sure of the acceptance and appropriateness of some behaviours after getting into a new environment that learning to judge behavioural value is often applied to reduce the uncertainties [5]. Overseas adaption has not been clearly defined by researchers. Ko [6] defined Overseas Adaption that an expatriate's perceived life satisfaction and work competence were the perceptions of foreign cultural value. Some researchers used to define cross-cultural adaption as the process of expatriates accommodating with culture shock in 
distinct cultural environments. According to Caligiuri [7], crosscultural adaption referred to an expatriate's new behaviours, norms, and roles integrated with the native culture, in spite of the acceptance of local culture [8], and was the psychological and emotional responses to new culture [9]. Cross-cultural adaption, therefore, was an internal, psychological, and emotional status, which could be measured by individual experiences in foreign culture.

Black [10] proposed work adaption, social life adaption to the host country, and general adaption. Nicholson and Imaizumi [11] pointed out Overseas Adaption as subjective happiness concept in various situations. Eovingood [12] discussed the factors in the adaption to job change from the seven dimensions of (1) distance, including the distance of job change, (2) country, referring to the leave of the original country, (3) job nature, whether the content and hierarchy of the new job being the same or different from the original one, (4) social support, whether the job change requiring moving alone or with family, (5) period, the time of tenure and the repatriation time, (6) repatriation, the possible expense and welfare resulted from deposition or demotion when not being able to change, and (7) voluntariness and intention, indicating individual control of the job change. Eovingood considered such dimensions as the critical dimensions to understand expatriate adaption, but different from the ones proposed by other researchers. Aycan [13] covered the dimensions of mental adaption, social-cultural adaption, and work adaption in Overseas Adaption; Shaffer et al. [14] applied work adaption, interactive adaption, and general adaption as the empirical dimensions; Wu et al. [15], referring to Black [10], divided cross-cultural adaption into work adaption, interactive adaption, and life adaption (General Adaption). Referring to the past researchers [14,16], Overseas Adaption is defined as the dimensions of Work adaption, life adaption, and interactive adaption in this study. (1) Work adaption refers to adapt to new position; (2) life adaption indicates the adaption to living environment, accommodation, and food; and (3) interactive adaption refers to adapting to the social life in the host country.

\section{Job satisfaction}

Smith et al. [17] pointed out Job Satisfaction as the differences between returns really acquired and estimated value in a specific environment that the less difference showed the higher satisfaction, and vice versa. Researchers presented distinct viewpoints on Job Satisfaction as the follows.

1. Overall satisfaction: Job Satisfaction was defined as a single concept that a worker could balance the satisfaction and dissatisfaction on the job to become a collective satisfaction. The concept of Job Satisfaction was, therefore, explained in general, without involving in the dimensions, factors, and processes.

2. Expectation discrepancy: Job Satisfaction was regarded as the difference between the returns really acquired and the estimated returns, where the less difference showed the higher satisfaction.
3. Frame of reference: Satisfaction was the result of an individual explaining the work characteristics according to the reference structure; i.e. the worker's emotional responses to various special dimensions.

Researchers also explained various opinions on the type of work dimensions. Smith et al. [17] covered the dimensions of work, promotion, salary, supervisors, and partners; other researchers divided Job Satisfaction into needs for survival, needs for relatedness, and needs for growth, including salary, welfare, supervisors, colleagues, safety, customers, and growth. There has not been the optimal classification for Job Satisfaction. Needs for survival, needs for relatedness, and needs for growth, proposed by Wu et al. [18], therefore, are used as the dimensions for Job Satisfaction in this study.

\section{Research hypothesis deduction}

Seashore and Taber [19] concluded environment and personal character as the factors in Job Satisfaction, which relied on the effects of the interaction on individual, organization, and society.

\section{Environmental factor}

(i) Political, economic, and cultural environments, such as unemployment rate.

(ii) Occupational character, like fame.

(iii) Internal environment of an organization, including organizational climate, organizational scale, and degree of centralization.

(iv) Work and work environment, like work characteristics.

\section{Personal attributes}

(i) Demographic variables, including age, gender, educational background, and seniority.

(ii) Stable personality trait, like psychological characters, value, and needs.

(iii) Ability, containing intelligence and skills.

(iv) Situational personality, such as motivation and preference.

(v) Perception, awareness, and anticipation.

(vi) Temporary personality trait, like anger and boredom.

In conclusion, the factors in Job Satisfaction could be classified into personal and environmental variables. Regarding personal variables, the effects of personal attributes are studied, whereas the effects of Overseas Adaption, as the environmental variable, on Job Satisfaction are explored in this study.

Based on the above points of view, the following hypotheses are proposed in this study: 
H1: Overseas Adaption shows significantly positive correlations with Needs for Survival in Job Satisfaction.

H2: Overseas Adaption reveals remarkably positive correlations with Needs for Relatedness in Job Satisfaction.

H3: Overseas Adaption presents notably positive correlations with Needs for Growth in Job Satisfaction.

H4: Gender presents remarkable moderating effects on the correlations between Overseas Adaption and Job Satisfaction.

H5: Age shows notable moderating effects on the correlations between Overseas Adaption and Job Satisfaction.

H6: Educational background presents significant moderating effects on the correlations between Overseas Adaption and Job Satisfaction.

H7: Marital status shows remarkable moderating effects on the correlations between Overseas Adaption and Job Satisfaction.

\section{Research method}

\section{$\underline{\text { Research framework }}$}

From the literature review of domestic and international researchers, the research framework is drawn to discuss the correlations between Overseas Adaption and Job Satisfaction.

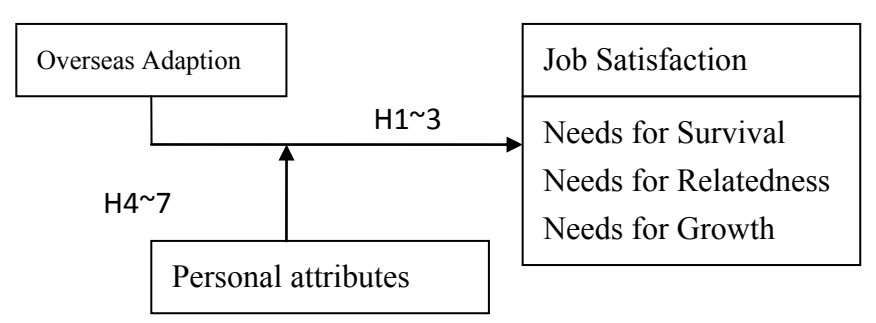

\section{Research subject and sampling}

Textile industry, one of the basic industries for career, is the entrepreneurial and the core business of Far Eastern Group and weights about a quarter of the entire revenue of the Group. The production factories were established in Taiwan, Southeast Asia, and Mainland China, and further established in Southeast Asia, including Singapore, Malaysia, Thailand, and Philippines since 1964. After Far-East Garment (Suzhou) being established in 1997, Far-East Cotton Mill (Wuxi), FarEast Dyeing (Suzhou), Far-East Industries (Jiujiang), and Oriental Industries (Suzhou) were continuously established. Far Eastern New Century therefore is selected as the research subject. The questionnaire survey is preceded through mails. With convenience sampling, a total of 400 copies are distributed to the expatriates of Far Eastern New Century, and 263 valid ones are retrieved, with the retrieval rate of $66 \%$. Within the valid copies, there are more male participants $(64 \%)$ than the female participants (36\%), the ones aged $21-30$ presents $56 \%$, 31-40: $37 \%, 41-50: 6 \%$, and $>50: 1 \%$; the ones with senior high school background shows $11 \%$, college background $68 \%$, and graduate background $21 \%$, as well as married ones reveals $16 \%$, single ones $73 \%$ and divorced ones $11 \%$.

\section{Analysis and discussion}

\section{Factor analysis of overseas adaption}

Referring to Overseas Adaptation Scale proposed by Shaffer et al. [14] and Kan [16], three factors, abstracted with confirmatory factor analysis (CFA), present the eigenvalue $>1$. Work adaptation (eigenvalue $=2.873, \alpha=0.82$ ) contains the requests and responsibility for current work, getting well along with colleagues, and the management of Taiwanese employees. Life Adaptation (eigenvalue $=2.251, \alpha=0.87$ ) includes the adaptation to getting along with other Taiwanese external to the company and the interaction with local Taiwanese. Interactive Adaptation (eigenvalue $=1.732, \alpha=0.84$ ) covers the adaptation to local transportation, local food, local weather and climate, local life, and local leisure and entertainment. The co-variance explained achieves $76.272 \%$.

The Job Satisfaction Scale extracted the factors of Needs for Survival (eigenvalue $=3.348, \alpha=0.86$ ), Needs for Relatedness (eigenvalue $=2.519, \alpha=0.85$ ), and Needs for Growth (eigenvalue $=1.241, \alpha=0.88$ ) with factor analysis. The covariance explained achieved $78.261 \%$.

\section{Correlation analysis of overseas adaption and needs for survival in job satisfaction}

With multiple regression analysis to test $\mathrm{H} 1$ (Table 1 ), the regression equation achieved the significance $(F=8.375$, $p<0.000)$. Overseas Adaption presented notable effects on Needs for Survival, where Life Adaption and Interactive Adaption showed significantly positive effects on Needs for Survival, both reaching the significance $(\beta=0.233, p<0.01$; $\beta=0.192, p<0.05)$; thus, $\mathrm{H} 1$ was partially supported.

\section{Correlation analysis of overseas adaption and needs for relatedness in job satisfaction}

With multiple regression analysis to test $\mathrm{H} 2$ (Table 1), the regression equation achieved the significance $(F=13.841$, $p<0.000)$. Overseas Adaption showed remarkable effects on Needs for Relatedness, where Work Adaption, Life Adaption, and Interactive Adaption showed notably positive effects on Needs for Relatedness, reaching the significance $(\beta=0.189$, $p<0.05 ; \beta=0.158, p<0.05 ; \beta=0.206, p<0.01)$; thus, $\mathrm{H} 2$ was supported.

\section{Correlation analysis of overseas adaption and needs for growth in job satisfaction}

With multiple regression analysis to test $\mathrm{H} 3$ (Table 1), the regression equation achieved the significance $(F=18.764$, $p<0.000)$. Overseas Adaption revealed significant effects on Needs for Growth, where Work Adaption, Life Adaption, and Interactive Adaption presented remarkably positive effects on 
Needs for Growth, reaching the significance $(\beta=0.164, p<0.05$; $\beta=0.175, p<0.05 ; \beta=0.215, p<0.01)$; thus, H3 was supported.

\section{Moderating effects of demographic variable}

\section{Effects of gender on the relations between Overseas Adaption and Job Satisfaction}

From analysis of variance (Table 2), gender showed notable moderating effects on the relations between Work Adaption $(p<0.05)$, Life Adaption $(p<0.01)$, and Needs for Survival, between Life Adaption $(p<0.01)$, Interactive Adaption $(p<0.05)$, and Needs for Relatedness, and between Work Adaption $(p<0.05)$, Interactive Adaption $(p<0.01)$, and Needs for Growth; thus, H5 was partially supported.

\section{Effects of age on the relations between Overseas Adaption and Job Satisfaction}

From analysis of variance (Table 3), age revealed notable moderating effects on the correlations between Life Adaption $(p<0.05)$, Interactive Adaption $(p<0.01)$, and Needs for Survival, between Life Adaption ( $p<0.01$ ), Interactive Adaption $(p<0.05)$, and Needs for Relatedness, and between Work
Adaption $(p<0.01)$, Life Adaption $(p<0.05)$, and Needs for Growth; thus, $\mathrm{H} 6$ was partially supported.

Effects of educational background on the relations between Overseas Adaption and Job Satisfaction

From analysis of variance (Table 4), educational background presented significant moderating effects on the correlations between Work Adaption $(p<0.01)$, Life Adaption $(p<0.01)$, and Needs for Survival, between Work Adaption $(p<0.05)$, Interactive Adaption $(p<0.01)$, and Needs for Relatedness, and between Work Adaption $(p<0.01)$, Life Adaption $(p<0.05)$ and Needs for Growth; thus, H7 was partially supported.

\section{Effects of marital status on the relations between Overseas Adaption and Job Satisfaction}

From analysis of variance (Table 5), marital status showed remarkable moderating effects on the correlations between Work Adaption $(p<0.05)$, Interactive Adaption $(p<0.01)$, and Needs for Survival, between Work Adaption $(p<0.01)$, Life Adaption $(p<0.05)$, and Needs for Relatedness, and between Life Adaption $(p<0.05)$, Interactive Adaption $(p<0.01)$, and Needs for Growth; thus, H8 was partially supported.

Table 1. Multiple regression analysis of Overseas Adaption and Needs for Growth.

\begin{tabular}{|l|c|c|c|}
\hline \multirow{2}{*}{} & \multicolumn{3}{|c|}{ Job satisfaction (dependent variable) } \\
\cline { 2 - 4 } & Needs for survival & Needs for relatedness & Needs for growth \\
\hline Overseas adaption (independent variable) & & & $0.164^{*}$ \\
\hline Life adaption & 0.102 & $0.189^{*}$ & $0.175^{*}$ \\
\hline Interactive adaption & $0.233^{* *}$ & $0.158^{*}$ & $0.215^{* *}$ \\
\hline$F$ & $0.192^{*}$ & $0.206^{* *}$ & 18.764 \\
\hline Significance & 8.375 & 13.841 & $0.000^{* * *}$ \\
\hline$R^{2}$ & $0.000^{* * *}$ & $0.000^{* * *}$ & 0.315 \\
\hline Regulated $R^{2}$ & 0.267 & 0.292 & 0.042 \\
\hline
\end{tabular}

Note: ${ }^{*} p<0.05,{ }^{* *} p<0.01,{ }^{* * *} p<0.001$.

Table 2. Effects of gender on the relations between Overseas Adaption and Job Satisfaction.

\begin{tabular}{|l|c|c|c|}
\hline Overseas adaption & Needs for survival $(p)$ & Needs for relatedness $(p)$ & Needs for growth $(p)$ \\
\hline Work adaption & $<0.05$ & $>0.05$ & $<0.05$ \\
\hline Life adaption & $<0.01$ & $<0.01$ & $>0.05$ \\
\hline Interactive adaption & $>0.05$ & $<0.05$ & $<0.01$ \\
\hline Hypothesis test & \multicolumn{2}{|c|}{ H5 partially supported } \\
\hline
\end{tabular}

Table 3. Effects of age on the relations between Overseas Adaption and Job Satisfaction.

\begin{tabular}{|l|c|c|c|}
\hline Overseas adaption & Needs for survival $(p)$ & Needs for relatedness $(p)$ & Needs for growth $(p)$ \\
\hline Work adaption & 0.05 & 0.05 & 0.01 \\
\hline Life adaption & 0.05 & 0.05 & 0.01 \\
\hline Interactive adaption & 0.01 & 0.01 & 0.05 \\
\hline Hypothesis test & \multicolumn{2}{|c|}{ H6 partially supported } \\
\hline
\end{tabular}


Table 4. Effects of educational background on the relations between Overseas Adaption and Job Satisfaction.

\begin{tabular}{|l|c|c|c|}
\hline Overseas adaption & Needs for survival $(p)$ & Needs for relatedness $(p)$ & Needs for growth $(p)$ \\
\hline Work adaption & 0.01 & 0.05 & 0.01 \\
\hline Life adaption & 0.01 & 0.05 & 0.05 \\
\hline Interactive adaption & 0.05 & 0.01 & 0.05 \\
\hline Hypothesis test & \multicolumn{3}{|c|}{ H7 partially supported } \\
\hline
\end{tabular}

Table 5. Effects of marital status on the relations between Overseas Adaption and Job Satisfaction.

\begin{tabular}{|l|c|c|c|}
\hline Overseas adaption & Needs for survival $(p)$ & Needs for relatedness $(p)$ & Needs for growth $(p)$ \\
\hline Work adaption & 0.05 & 0.01 & 0.05 \\
\hline Life adaption & 0.05 & 0.05 & 0.05 \\
\hline Interactive adaption & 0.01 & 0.05 & 0.01 \\
\hline Hypothesis test & \multicolumn{3}{|c|}{ H8 partially supported } \\
\hline
\end{tabular}

\section{Conclusion}

From the data analysis and research conclusion, the practical applications of Overseas Adaption and the suggestions for future research are proposed. The effects of Overseas Adaption on Job Satisfaction are regarded as the primary indicators. Consistent with the past research [20-22], Life Adaption, Work Adaption, and Interactive Adaption in Overseas Adaption show significant effects on Job Satisfaction.

The research results present the direct correlations between Overseas Adaption and Job Satisfaction of expatriates in textile industry that the work adaption, life adaption, and interactive adaption should be enhanced. Supportive activities for the expatriates should also be enhanced. For instance, the employees with expatriation experiences could share the experiences and knowledge, and educational trainings could be preceded for the simulation so that the expatriates could better know about the tasks and easily get into the overseas tasks and living. Shortterm business trips could have the expatriates accumulate the overseas experiences; and, overseas expatriate handbook could be offered for instantaneously solving similar problems.

\section{References}

[1] Lin, Tang-Yu: Taiwan's textile industrial structure and an analysis of the effectiveness of government policy, Taiwan Bank Quarterly, Vol. 43, No. 2, pp. 134-166, 2002.

[2] Chen Yeong sun: Current situation of China's textile industry outlook and solution, Industrial Finance, Vol. 32, pp. 34-49, 2001.

[3] Huang li Zhu: Taiwan's Textile Industry Development History and Characteristics, Journal of Geographical Science, Vol. 18, pp. 59-89, 2005.

[4] Oberg, K.: Culture shock $\square$ Adjustment to new cultural environments. Practical Anthropology, Vol. 7, pp. 177-182, 1960.

[5] Brislin, R. W.: Cross-cultural encounters, New York: Pergamon Press, 1981.

[6] Ko, Yuan-ta: The adaptation study for Taiwanese expatriates in China, Journal of Chinese Management Review, Vol. 4, No. 1, pp. 21-35, 2010.
[7] Caligiuri, M. P.: Selecting expatriates for personality characteristics: A moderating effect of personality on the relationship between host national contact and crosscultural adjustment, Management International Review, Vol. 40, No. 1, pp. 61-80, 2000.

[8] Church, A. T.: Sojourner Adjustment, Psychological Bulletin, Vol. 91, pp. 540-571, 1982.

[9] Black, J. S.; Mendenhall, M.: Cross-cultural training effectiveness: A review and a theoretical framework for future research, Academy of Management Review, Vol. 15, No. 1, pp. 113-136, 1990.

[10] Black, J. S.: Work role transitions - A study of American expatriate managers in Japan, Journal of International Business Studies, Vol. 19, No. 2, pp. 277-294, 1988.

[11] Nicholson, N., Imaizumi, A.: The adjustment of Japanese expatriates to living and working in Britain, British Journal of Management, Vol. 4, pp. 119-134, 1993.

[12] Eovingood, D. F.: A study of reported relationship between adjustment problems and job relocation to America for foreign expatriate, Peabody College of Vanderbilt University, Doctoral Dissertation, 1995.

[13] Aycan, Z.: Expatriate adjustment as a multifaceted phenomenon: Individual and organization level predictors, The International Journal of Human Resource Management, Vol. 8, No.4 pp. 434-456, 1997.

[14] Shaffer, M. A.; Harrison, D. A.; Gilley, K. M.: Dimensions, determinants, and differences in the expatriate adjustment process, Journal of International Business Studies, Vol. 30, pp. 557-581, 1999.

[15] Wu, Wan-yi; Chen, Shuo-pei; Kan, Pei-shan: An empirical research on the effectiveness of cross-cultural training for expatriate managers, NTU Management Review, Vol. 10, No. 2, pp. 167-203, 2010.

[16] Kan, Pei-shan: An empirical research on the effectiveness of cross-cultural training for expatriate managers, Journal of National Chengchi University, Vol. 35, pp. 13-56, 2010.

[17] Smith, P. C.; Kendall, L. M.; Hullin, C. L.: The measurement of satisfaction in work \& retirement, Chicago: Rand Mcnally, 1969.

[18] Wu, Wan-yi; Tsai, Min-tien; Lin, Chia-tzu: The evaluation of expatriate's working performance and its influence factors The companies in Taiwan investing in mainland for example, Management Review, Vol. 18, No. 3, pp. 1-34, 2009. 
[19] Seashore, S. E.; Taber, T. D.: Job satisfaction and their correlations, American Behavior Scientist, Vol. 18, pp. 333-368, 1975.

[20] Shumsky, N. J.: Justifying the intercultural training investment, The Journal of European Business, Vol. 4, pp. 38-43, 1992.
[21] Lin, Min-hung: A study of adjustment factors and indicators for the expatriates of Taiwan business, Journal of Chihlee Institute of Technology, Vol. 12, pp. 89-111, 2012.

[22] Wang, Chen-chang: Research of overseas adaptation and job satisfaction in expatriates - A survey of Taiwanese computer firm in China, Sun Yat-Sen Management Review, Vol. 3, No. 4, pp. 64-75, 2012. 